\title{
3D CITY MODELS FOR SUPPORTING SIMULATIONS IN CITY DENSIFICATIONS
}

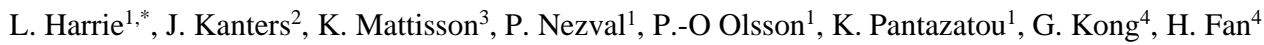 \\ ${ }^{1}$ Department of Physical Geography and Ecosystem Science - Lund University, Sweden - \\ lars.harrie@ nateko.lu.se,pe0117ne-s@student.lu.se,per-ola.olsson@nateko.lu.se,karolina.pantazatou@nateko.lu.se \\ ${ }^{2}$ Department of Architecture and Built Environment - Lund University, Sweden - jouri.kanters@ebd.lth.se \\ ${ }^{3}$ Department of Laboratory Medicine - Lund University, Sweden - Kristoffer.Mattisson@ med.lu.se \\ ${ }^{4}$ Department of Civil and Environmental Engineering - Norwegian University of Science and Technology, Norway - \\ hongchao.fan@ntnu.no
}

KEY WORDS: 3D City Models, Noise Simulations, Daylight Simulations, Urban Planning, City Densifications

\begin{abstract}
:
In order to meet the increasing needs of housing and services in urban areas, cities are densified. When densifying a city, it is important to provide good living conditions while maintaining a low environmental impact. To ensure this, the urban planning process should include simulations of e.g. noise and daylight conditions. In this paper we describe a newly started projected directed towards the need for quality-assured and harmonised input data to the simulations, in the form of 3D city models. The first part of the paper includes the background and research questions of the project and in the second part a tool for daylight simulations on neighbourhood level is introduced, a tool that will be utilized for evaluating the 3D city model design.
\end{abstract}

\section{INTRODUCTION}

In order to meet the increasing needs of housing and services in urban areas, cities are densified. When densifying a city, it is important to provide good living conditions while maintaining a low environmental impact to ensure a sustainable development. To achieve this, the urban planning process undertakes several steps including communication with relevant stakeholders and the public. At the early stages of the planning process, alternative designs of the planned buildings and infrastructure can be evaluated e.g., by using simulations and parametric modelling. However, the possibility of using simulations in the urban planning process has not reached its full potential in most countries. There are several reasons for this underutilisation. One main reason is that the (legal) planning process, and the legal documents associated with it, are not designed for new digital opportunities. Another reason is that simulations are hampered by a lack of adapted, qualityassured and harmonised input data, e.g., in the form of 3D city models. In this paper, a newly started project is described that addresses the latter issue with the focus on noise and daylight simulations. The noise that is of main interest here is the one generated by traffic, industries, etc., while noise generated by e.g., a person him-/herself or loud neighbours are not included. In daylight we include both the passive use (in indoor as well as outdoor environments) and active use (photovoltaic and solar thermal). However, other building energy simulations, not concerned with daylight, are not included in this study (as in e.g., Wate \& Coors 2015).

In the first part of the paper, the background and research questions of the project are described and in the final part development of a simulation tool is described. The project is designed in a Swedish context, but much of the content is universal.

\subsection{Data flow to support noise and daylight simulations}

The vision is to design, create and maintain a $3 \mathrm{D}$ city model that supports noise and daylight simulations (Figure 1). The 3D city

\footnotetext{
${ }^{1}$ https://www.smartbuilt.se/projekt/informationsinfrastruktur/3cim/

${ }^{2} \mathrm{https} / / / \mathrm{www}$. lantmateriet.se/sv/webb/smartare-

samhallsbyggnadsprocess/nationella-specifikationer/
}

model will be based on a forthcoming Swedish profile of CityGML (that is currently under development in the national project $\left.3 \mathrm{CIM}^{1}\right)$. This national profile will likely need to be extended with some additional information which hopefully could be added to the Swedish profile in the future. To ensure that the $3 \mathrm{D}$ city model is up to date, there is currently ongoing work to map the $3 \mathrm{D}$ city model to the municipality $2 \mathrm{D} / 3 \mathrm{D}$ databases, as well as defining national specifications for the 2D/3D geodatabases (as part of the governmental mission Smartare Samhällbyggnadsprocess ${ }^{2}$ ).

The detailed development plans (the legal document that regulates what is allowed to be built on an area in Sweden) have an important role in the simulations (Kanters \& Wall, 2018). Some detailed development plans regulate in detail what is allowed to be built, defining e.g., the building envelopes. In this case, it is important that simulations are performed already during the creation process of the detailed development plans. In other cases, the detailed development plans are more open and set a framework of what is allowed to be built. This implies that the detailed development plans could work as input to the simulation tools, where their imbedded regulations act as constraints in the simulations. So far, few simulation tools allow this import, but this will likely change as an effect of a new Swedish law that requires that all future detail development plans must be machine readable ${ }^{3}$.

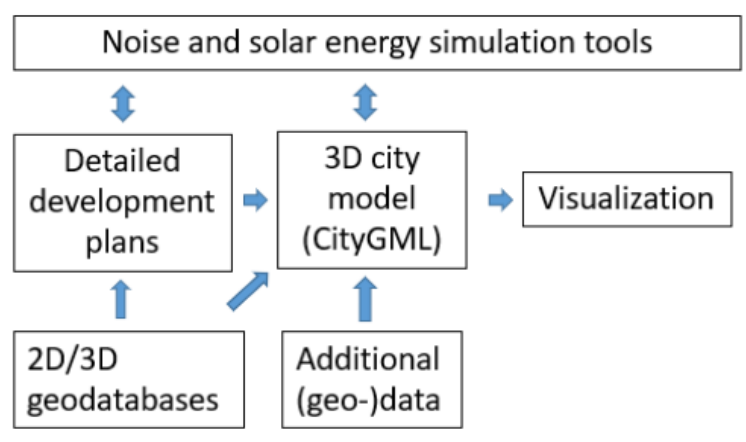

Figure 1. Data flow to support simulations.

\footnotetext{
${ }^{3} \mathrm{https}: / / \mathrm{www} \cdot$ boverket.se/sv/samhallsplanering/digitalisering/digitalis ering-av-planeringsprocessen/digitala-detaljplaner/
} 
The simulation tools should be able to export their results back to the 3D city models. This export should include proposed buildings (envelopes), if such are created in the simulations, as well as estimated noise / solar daylight values on e.g., façades. These estimated values should then be possible to visualise together with the current 3D city model. This approach requires that the $3 \mathrm{D}$ city model can handle future scenarios, which is proposed to be included in the new CityGML 3 conceptual model (cf. Chaturvedi et al. 2016).

\subsection{Noise simulations}

The European Union (EU) has formulated the Environmental Noise Directive (END; 2002/49/EC) as a common management plan to deal with urban noise. The Directive requires member states to determine the citizens' exposure to noise through simulations. Details of how to perform noise simulations aligned with END is provided by the Common framework for Noise aSSessment methOdS (CNOSSOS; Kephalopoulos et al., 2012). The CNOSSOS framework includes details of how noise is generated by road traffic, railway traffic, aircrafts and industries as well as details of how the noise propagation should be estimated. However, CNOSSOS does not include details of how the physical environment should be modelled (Kumar et al., 2020), i.e., there is no details of how the obstacles (e.g., building and noise barriers) should be modelled. Examples of input data for the simulations that should be retrieved from the city model are building usage, number of floors, height, and dwellings.

Additional noise simulation models are presently used in Sweden, such as the NV 96 and Nord2000. These models are used on a detailed level and are important in e.g., the creation of detailed development plans (Ögren \& Ryberg 2015). The models demand similar data as CNOSSOS, but the level of detail varies between the models. For instance, CNOSSOS and Nord2000 use 5 classes of vehicles, while NV 96 only uses two.

There is a number of sources of uncertainty in noise simulations related to method, data and parameter settings. In this project we focus on the harmonisation of the input data. We will use 3D city models based on the forthcoming Swedish profile of CityGML. This profile will include a national measuring guideline that e.g., describes the obstacles (buildings, walls, etc.) in more detail. But even though there is a common measuring guideline, the data will not be fully harmonised, partly since various data collection techniques can be used. One issue to investigate is whether it is sufficient to rely on measuring guidelines (and if so, how these should be defined) or if there must be a common national data collection strategy specifically for noise modelling (cf. Stoter et al. 2020 who argues for the latter).

\subsection{Daylight simulations}

Kanters et al. (2021) conducted a series of workshops with urban planners in two Swedish municipalities concerning how they consider solar access in their planning. The study revealed that currently, the urban planners consider the daylight requirements indoors, but very seldom the sunlight access on the building envelope and the outdoor environment, and they almost never consider active use of daylight (for e.g., photovoltaic applications such as solar panels). Reasons for this is a lack of normative rules (legislation and/or practice), lack of solar access metrics for outdoor environment (including threshold values) and lack of suitable tools and input data. This situation is unsatisfactory since there is a need to include daylight and solar access in early phases in the urban planning (Lundgren and Dahlberg 2018); the current practice of separating urban space design and solar access planning is not a good solution for the future.

The detailed design of the indoor daylight is done by architects/engineers at a later stage in the building design process, since it is a legal requirement in the building permit process. These requirements will be enhanced when Sweden adopts the new European standard for daylight simulations (EN 17037:2018). This standard includes stricter rules for daylight conditions, e.g., threshold values for daylight conditions in rooms and direct solar access on windows for a certain time period. Obtaining good indoor daylight conditions is important, among other it has been shown that access to incoming daylight increases the employers' productivity and real estate value (Turan et al., 2020; Yang \& Nam, 2010).

To evaluate the indoor daylight requirements in future buildings, simulations are essential. There are several simulation tools based on Computer Aided Design (CAD) and Building Information Modelling (BIM) that can perform daylight simulations but most of these tools are designed for single buildings, or small groups of buildings, and are therefore not suitable for city densification studies or for design of new neighbourhoods (see e.g. Kanters \& Wall, 2016; Jakica, 2017; Eicker et al., 2014). There are also solar energy tools for larger areas, mainly based on GIS and 3D city models, but these tools seldom include simulations of indoor daylight conditions. Furthermore, many of these tools only consider roofs, which is often insufficient in Sweden which at equinox (around $21^{\text {st }}$ of March/September) has a solar altitude of 22 degrees in Northern part and 35 degrees in Southern part at noon (see e.g., Dubois et al. 2019).

There is an increasing research interest to perform daylight simulations in larger areas. Within the international Solar Heating and Cooling programme there is a project Solar Neighborhood planning ${ }^{4}$ that address both the active use of daylight (solar thermal technologies and photovoltaics) and the passive (well-being of humans in both indoor and outdoor environments). One subtask within this project concerns solar planning tools on the neighbourhood level. Our project will cooperate with this subtask concerning the requirement of the input data to the solar planning tools.

There are no requirements on the input data to daylight simulations in the current Swedish legislation nor in the EN 17037:2018 standard. In general, the simulations require geospatial data (building surfaces, digital elevation model and vegetation data) and weather data. Fenestration (openings in the building envelope) details are also interesting from an indoor perspective. Another important factor in daylight simulations in a high latitude country such as Sweden is the reflectance properties of façades. This is important since a large portion of the indoor daylight (in dense areas) is reflected from other buildings (Dubois et al. 2019).

3D City models are attractive to be used for daylight simulations since they potentially include all the geospatial data required. Standardized 3D city models would also entail a good possibility to harmonize the simulations on a national level. Currently, most 3D city models (in Sweden) are in LOD2 and lack necessary window information (and reflectance properties). In the context of city densifications, windows for planned buildings (as well as reflectance properties) can be extracted from BIM (cf. Huang et

\footnotetext{
${ }^{4}$ https://task63.iea-shc.org/
} 
al. 2020) and for existing buildings from street view images (cf. Kong and Fan, 2021). An important issue here is also the requirement of the data quality of the $3 \mathrm{D}$ city models to support accurate simulations, which has e.g., been studied by Biljecki et al. (2015).

Several of the urban planners that participated in the workshops arranged by Kanters et al. (2021) argued that they need easy to use (daylight) simulation tools to be able to iterate and evaluate design proposals. To realize this in practice, it is important that the simulation results can be exported and visualized together with other information. Also, here the 3D city models are crucial since they have the potential to include simulation results and create scenarios. A prerequisite here is that there are objects in the city model which can store the simulation result, e.g., window objects that could store daylights metrics (as used in e.g., EN 17037:2018) and façade/roof objects that could store e.g., estimated irradiation (both in vertical/horizontal and optimal direction). These simulation values could be both static and dynamic; for the latter one issue to study in this project is how this dynamic information could be stored using the Dynamizer module in CityGML3, see Kutzner et al. (2020). Visualizations in the planning stages are also important to be able to evaluate the aesthetic aspects of adding e.g., solar panels on roofs and façades (for a discussion about this need see Lundgren \& Dahlberg 2018).

\section{DESIGN AND IMPLEMENTATION OF A TOOL FOR SOLAR METRICS ESTIMATION}

The main focus in our project is to study requirement of input data to noise and daylight simulations, but in parallel we tailor/develop some tools for testing the data models. For our studies of simulation of (yearly) irradiation on windows for larger areas, applicable for e.g., a city densification project, we want an open source platform. We decided to use the platform The Urban Multi-scale Environmental Predictor ${ }^{5}$ (UMEP; Lindberg et al., 2018) which is a QGIS plug-in of the SEBE model (Lindberg et al., 2015). UMEP is, among others, capable of simulating irradiation on façades and roofs for large areas. Input to the simulations are a digital surface model (DSM; that could include building, vegetation, etc.) and building footprints. From our requirements, UMEP has two shortcomings:

1) It does not include window information.

2) It cannot export the result to a $3 \mathrm{D}$ city model.

Therefore, we developed an own (open source) tool to solve these shortcomings in the UMEP platform.

\subsection{Implementation details}

Figure 2 describes the main workflow of our tool (for details, see Nezval, 2021). The tool uses the simulated energy values from UMEP (on both roofs and façades) as input and links these values to buildings in a city model (stored in CityJSON) that includes windows. Then the irradiation is estimated on window level, facades as well as roofs and the result is exported back to the city model. The tool is implemented in Python and is available on GitHub 5 .

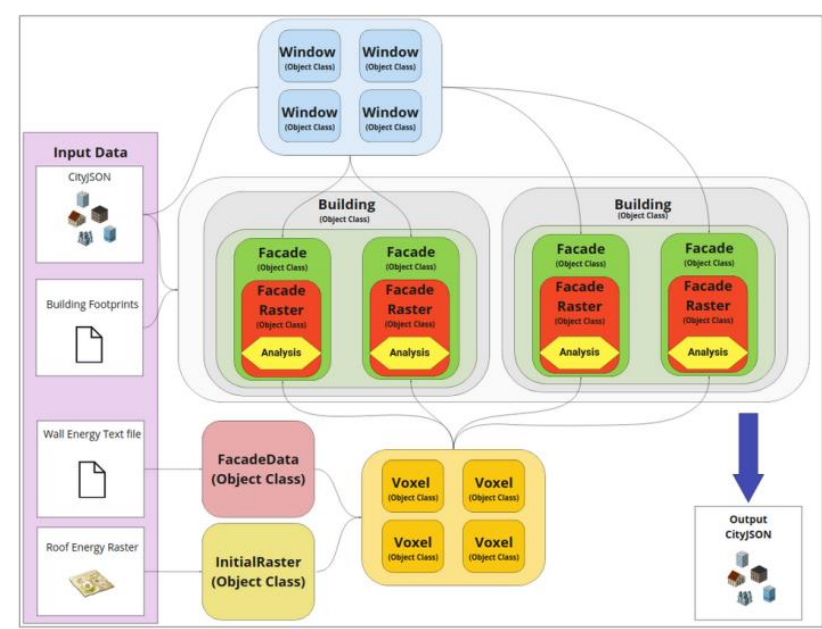

Figure 2. Main workflow of the tool.

\section{EVALUATION OF THE TOOL}

Evaluation of the tool should ideally be done using a city model in at least LOD2 with window information (based on the forthcoming Swedish national standard). Since this data is not available yet (the available city model does not contain any window information nor is it following the CityGML/CityJSON standard), we created our own input data for a first evaluation of the tool.

\subsection{Study area}

The study area is located in the Spoletorp neighborhood, near the Central station, in the city of Lund, Scania Sweden (Figure 3). The buildings in the area are already constructed, the focus in this paper is on evaluating the tool.
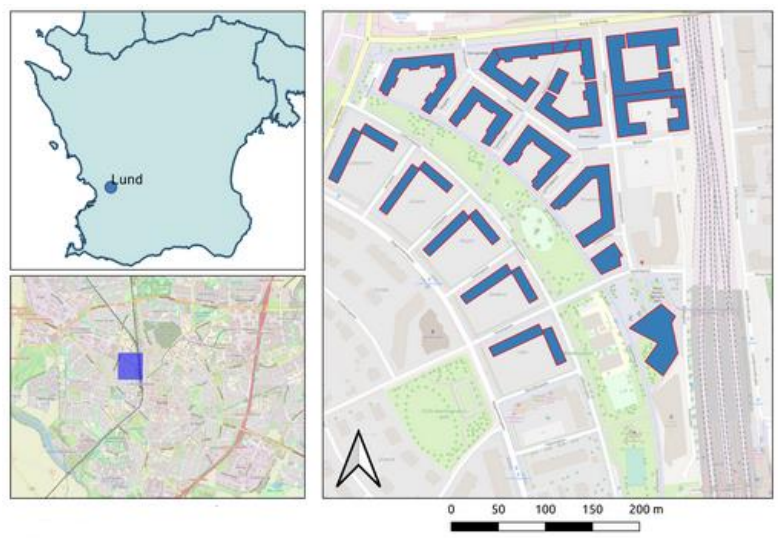

Figure 3. Study Area in Lund. Approximate coordinates of the area are $55.709^{\circ} \mathrm{N}$ and $13.186^{\circ} \mathrm{E}$. Source data: OSM, DivaGIS.

\subsection{Creation of 3D building input data}

The 3D building data with window information (top left in Figure 2) were created from street images and building footprints using an interactive platform (developed by Fan et al., 2021) as described in Figure 4. The approach is based on a convolutional neural network $(\mathrm{CNN})$ to automatically detect the bounding boxes of windows and doors on facades of these buildings (Kong and Fan, 2021). The CNN approach achieves good results for

\footnotetext{
${ }^{5}$ https://github.com/petnez9/daylight_estimation_tool
} 
facade parsing of windows, doors, balconies, roofs, and shops by combing pixelwise segmentation and global object detection. In this study, Google Street View images were used as the streetlevel image data source. The locations, sizes, and layouts of windows and doors on the facades were semi-automatically corrected from perspective distortion and some detect errors by using the interactive platform. Then, the georeferencing was conducted manually by registering corresponding façade images with their building footprint edges obtained from Open Street Map (OSM). The challenges in the study area are: (1) the lower windows are often hidden by trees in the images, (2) the lengths of some facades are too long to be covered in one street-level images, which makes the correction of windows and doors and georeferencing more difficult. Hence, some extra interactive work was necessary. Currently, roof structures are simply modelled as flat planes; this is not ideal but sufficient to evaluate the performance of our tool. The resulting 3D building models, illustrated in Figure 5, are stored in CityJSON.

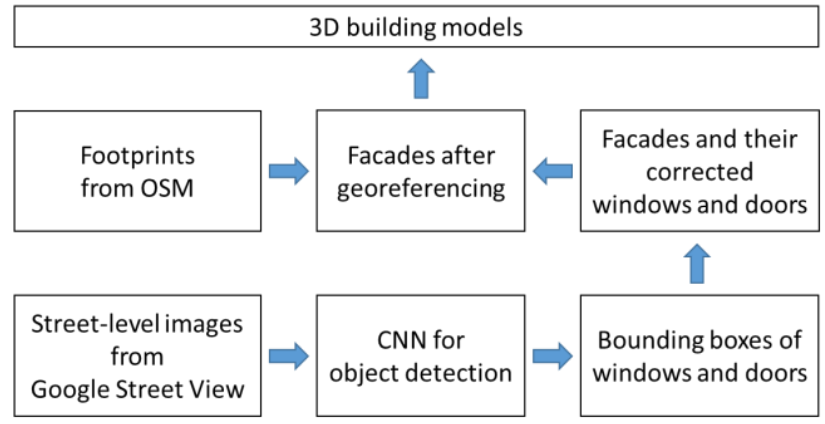

Figure 4. The framework of 3D building reconstruction for creating the input data.

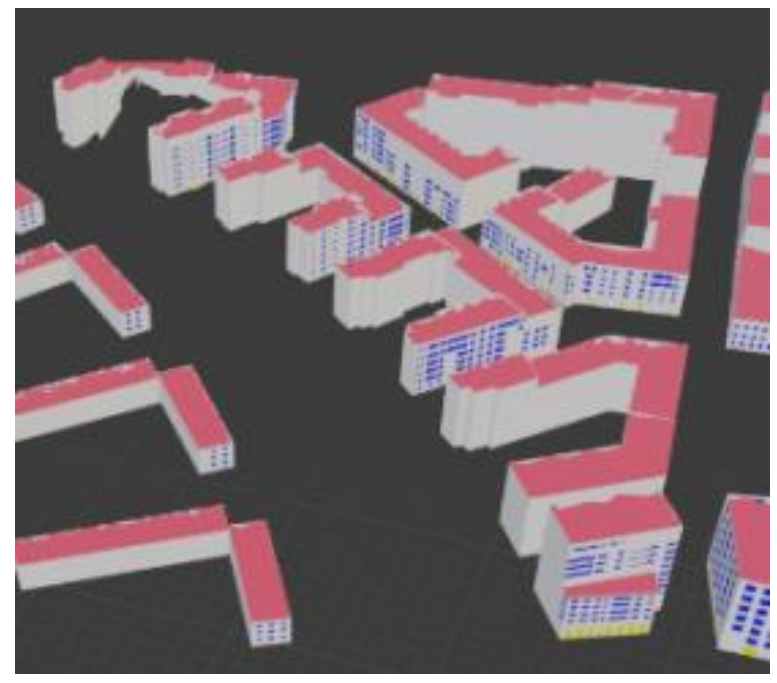

Figure 5. 3D building objects in the study area.

\subsection{Simulation with UMEP}

The DSM for the simulations was created by the 3D building objects in Figure 5 and a digital elevation model (DEM) from the Swedish mapping, cadastral and land registration authority (Lantmäteriet) with $2 \mathrm{~m}$ spatial resolution. The DSM was then resampled to $1 \mathrm{~m}$, which is then the geometrical resolution in the simulations. Figure 6 illustrates the simulated irradiation values (which are stored in the bottom left files in the workflow in Figure 2).

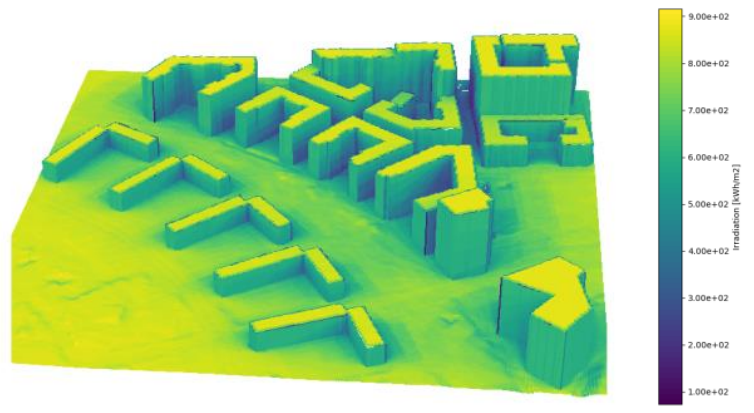

Figure 6. Annual solar irradiation values of the buildings in the study area simulated by UMEP.

\subsection{Application of the tool and export of simulation result}

Our tool computed the irradiation values for the windows (in Figure 5) based on the UMEP simulation result (in Figure 6). The irradiation values were then stored as attributes in the CityJSON file.

\subsection{Future development}

Three future steps are: (1) to study the effect of densifications (new buildings) on solar irradiance in the study area, (2) estimate and visualise dynamic solar irradiance values (of interest here could e.g., be the new Dynamizer module in CityGML3, see Kutzner et al. 2020) and (3) link the simulations to the detailed development plans.

\section{CONCLUDING REMARKS}

The workflow in Figure 1 assumes that there is an advantage of using a standardised 3D city model for noise and energy simulations. This is recommended in much academic literature (e.g., Kumar et al., 2020), but in production it is still more common to map the (geo-) data sources directly to the simulation tools. The arguments to use a standardised 3D city model is that it better harmonises the data, that scenarios can more easily be shared by simulation tools and that visualisations can be created that incorporates result from several simulation tools. But these advantages need to be verified in practical studies, which we aim to perform in this project e.g., by using tools similar to the one described above.

\section{ACKNOWLEDGEMENTS}

The study is financed by Formas grant 2020-01460. We thank Fredrik Lindberg, Gothenburg University, for help with the UMEP tool.

\section{REFERENCES}

Biljecki, F., Heuvelink, G.B.M., Ledoux, H., \& Stoter, J., 2015: Propagation of positional error in 3D GIS: estimation of the solar irradiation of building roofs. IJGIS, 29:12, 2269-2294.

Chaturvedi K., Smyth C. S., Gesquière G., Kutzner T., \& Kolbe T. H., 2016: Managing Versions and History Within Semantic 3D City Models for the Next Generation of CityGML. In Advancing Geoinformation Science for a Changing World; Springer Science and Business Media LLC, 191-206.

Duois, M.-C., Gentile., N., Laike, N., T., Bournas, I., \& Alenius, M., 2019: Daylight and lighting - under a Nordic sky. Studentlitteratur, Lund. 
Eicker, U., Nouvel, R., Duminil, E., Coors, V., 2014: Assessing passive and active solar energy resources in cities using 3D city models. Energy Proced., 57, 896-905.

Fan, H., Gefei, K., Chaoquan, Z., 2021: An Interactive platform for low-cost 3D building modeling from VGI data using convolutional neural network. Big Earth Data. vol. 5 (1).

Gefei, K., Fan, H., 2021: Enhanced Facade Parsing for StreetLevel Images Using Convolutional Neural Networks. IEEE Transactions on Geoscience and Remote Sensing.

Huang, W., Olsson, P.-O., Kanters, J., and Harrie, L.: Reconciling city models with BIM in knowledge graphs: a feasibility study of data integration for solar energy simulation, ISPRS Ann. Photogramm. Remote Sens. Spatial Inf. Sci., VI4/W1-2020, 93-99.

Jakica, N., 2017: State-of-the-art review of solar design tools and methods for assessing daylighting and solar potential for building-integrated photovoltaics. Renewable and Sustainable Energy Reviews. https://doi.org/10.1016/j.rser.2017.05.080.

Kanters, J., Wall, M., 2016: A planning process map for solar buildings in urban environments. In Renewable and Sustainable Energy Reviews (Vol. 57, pp. 173-185). Elsevier Ltd.

Kanters, J., Wall, M., 2018: Experiences from the urban planning process of a solar neighbourhood in Malmö, Sweden, Urban, Planning and Transport Research. doi: $10.1080 / 21650020.2018 .1478323$.

Kanters, J., Gentile, N. \& Bernardo, R., 2021: Planning for solar access in Sweden: routines, metrics, and tools. Urban, Planning and Transport Research, 348-368.

Kephalopoulos S., Paviotti M., Anfosso-Lédée F.., 2012: Common Noise Assessment Methods in Europe (CNOSSOSEU); Publications Office of the European Union: Brussels, Belgium, JRC72550.

Kumar, K., Ledoux, H., Schmidt, R., Verheij , T., Stoter, J., 2020: A Harmonized Data Model for Noise Simulation in the EU. ISPRS Int. J. Geo-Inf., 9, 121.
Kutzner, T., Chaturvedi, K. \& Kolbe, T.H., 2020. CityGML 3.0: New Functions Open Up New Applications. PFG - Journal of Photogrammetry, Remote Sensing and Geoinformation Science, 88, 43-61. https://doi.org/10.1007/s41064-020-00095-z

Lindberg, F., Jonsson, P., Honjo, T., \& Wästberg, D., 2015: Solar energy on building envelopes $-3 \mathrm{D}$ modelling in a 2D environment. Solar Energy, 115, 369-378.

Lindberg, F., Grimmond, C.S.B., Gabey, A., Huang, B., Kent, C.W., Sun, T., Theeuwes, N., Järvi, L., Ward, H., Capel-Timms, I., Chang, Y.Y., Jonsson, P., Krave, N., Liu, D., Meyer, D., Olofson, F., Tan, J.G., Wästberg, D., Xue, L., \& Zhang, Z., 2018: Urban Multi-scale Environmental Predictor (UMEP) - An integrated tool for city-based climate services. Environmental Modelling and Software. 99, 70-87,

https://doi.org/10.1016/j.envsoft.2017.09.020

Lundgren, M. \& Dahlberg, J. (eds), 2018: Approaches, Methods and Tools for Solar Energy in Urban Planning. IEA SHC Task 51/ Report B2. Available at: https://task51.iea-shc.org/publications.

Nezval, P., 2021: Design, implementation and evaluation of a daylight estimation tool using $3 D$ city model data. MSc thesis, Department of Physical Geography and Ecosystem Science, Lund University, Manuscript.

Stoter, J., Peters, R., Commandeur, T., Dukai, B., Kumar, K., Ledoux, H., 2020: Automated reconstruction of 3D input data for noise simulation. Comput. Environ. Urban Syst. 80, 101424.

Turan, I., Chegut, A., Fink, D., Reinhart, C., 2020: The value of daylight in office spaces. Building and Environment, 168, 106503.

Wate, P., \& Coors, V. 2015: 3D Data Models for Urban Energy Simulation. Energy Procedia, 78, 3372-3377.

Yang, I.-H., \& Nam, E.-J., 2010: Economic analysis of the daylight-linked lighting control system in office buildings. Solar Energy, 84(8), 1513-1525.

Ögren , M., \& Bengtsson Ryberg, J.., 2015: Bullerberäkningar med Cnossos-EU i Sverige. Västra Götalandsregionens Miljömedicinska Centrum Report in Swedish. 